\title{
Commentary: There is strength in heart teams, whether or not the numbers add up
}

\author{
Moritz C. Wyler von Ballmoos, MD, and \\ Michael J. Reardon, MD \\ "None of us is as smart as all of us" \\ -Ken Blanchard
}

The concept of a multidisciplinary team approach to cardiothoracic disease treatment has long been used in areas such as thoracic oncology and transplantation. More recently, this approach has extended to coronary disease and aortic stenosis based on studies such as Synergy Between Percutaneous Coronary Intervention with TAXUS and Cardiac Surgery ${ }^{1}$ and randomized trials for the evaluation of transcatheter aortic valve replacement (TAVR). ${ }^{2,3}$ The $\mathrm{US}^{4}$ and European $^{5}$ valve guidelines now both suggest heart team evaluation as a class I recommendation for the treatment of severe aortic stenosis-but with a level of evidence C. Robust comparative studies for what intuitively makes sense; that is, approaching patient scenarios not as an individual specialty but rather as a multidisciplinary team, are lacking. As a field, we should attempt to base our recommendations on the best data available and not just expert opinion, even if that expert opinion is widely held to be true.

Porterie and colleagues from Laval University in Québec ${ }^{6}$ suggest evaluating the question of whether or not a heart team approach to octogenarians undergoing surgical aortic valve replacement (SAVR) improves outcomes. Specifically, they retrospectively compare surgical treatment and outcomes in patients from 2 distinct clinical pathways: patients referred to a multidisciplinary heart team for TAVR, and patients referred for SAVR directly to surgeons at the same institution. The authors studied 528 patients aged 80 years or older referred to their institution for

From the Department of Cardiovascular Surgery, Houston Methodist Hospital, Houston, Tex.

Disclosures: The authors reported no conflicts of interest.

The Journal policy requires editors and reviewers to disclose conflicts of interest and to decline handling or reviewing manuscripts for which they may have a conflict of interest. The editors and reviewers of this article have no conflicts of interest.

Received for publication March 8, 2021; revisions received March 8, 2021; accepted for publication March 9, 2021; available ahead of print March 12, 2021.

Address for reprints: Michael J. Reardon, MD, Department of Cardiovascular Surgery, Houston Methodist Hospital, 6550 Fannin St, Suite 1401, Houston, TX 77030 (E-mail: mreardon@houstonmethodist.org).

J Thorac Cardiovasc Surg 2023;165:1020-1

$0022-5223 / \$ 36.00$

Copyright (c) 2021 by The American Association for Thoracic Surgery

https://doi.org/10.1016/j.jtcvs.2021.03.029

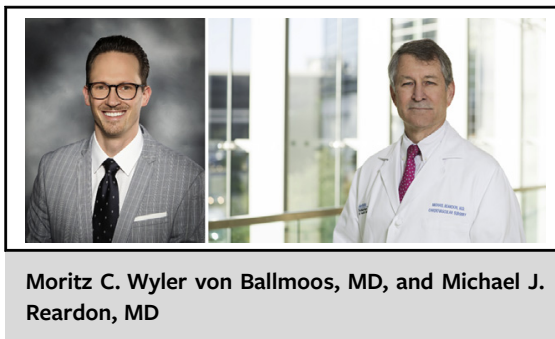

CENTRAL MESSAGE

The value of heart teams in cardiac surgery may be difficult to measure, but the value is real and gains importance as case and patient complexity increase.

TAVR and seen by their heart team between 2007 and 2016. Of these, 101 after heart team discussion were redirected to SAVR by 3 different surgeons who are part of the heart team. They then compared these with a select group from 506 patients during the same time period referred directly for SAVR performed by 10 different surgeons (including the 3 heart team surgeons) but without having a heart team evaluation. As such, the exposure of interest for this study should be considered evaluation by a heart team and the actual procedure (ie, SAVR) and related variables (eg, crossclamp time) are intermediate variables on the causal pathway.

A priori, patients referred for TAVR (and therefore seen by a heart team) and those sent directly to a surgeon for SAVR tend to be 2 different cohorts from the larger population of patients with aortic stenosis. This is notably evidenced by the much higher prevalence of concomitant coronary artery bypass graft procedures, and hence longer procedure times, in the group that was not evaluated by a heart team. Appropriately, these higher-risk patients with coronary artery disease who had indications for revascularization are preferentially referred to surgeons directly, rather than to a heart team for TAVR evaluation. On the flipside are patients excluded from TAVR for anatomic reasons, concomitant pathology, and low surgical risk. All this makes a comparison of the groups tricky. The concern for these selection biases persists, despite propensity score matching; an analysis restricted to all isolated SAVR or low-risk patients might have provided a clearer picture. The authors make a valiant effort to find exchangeability, and the validity of the proposed comparison ultimately is 
open to discussion. After matching, only $14 \%$ of patients in either exposure group (ie, with or without heart team evaluation) were eventually included in the analysis. More than $85 \%$ of the analyzed cases in both groups were performed by the 3 heart team surgeons, despite the fact that $70 \%$ of all the patients in the directly referred group without heart team input were operated on by 7 other surgeons and reportedly had significantly lower stroke rates. Whether these highly selected individuals chosen for analysis from 2 arguably different patient cohorts offer meaningful comparisons is left for the reader to decide. Ultimately, the study reports an association of the exposure with several short-term but not long-term outcomes.

The authors suggest that the improved outcomes may be related to the heart team's opportunity for in-depth screening of patients for noncardiac disease and risk factors such as renal, pulmonary, or cognitive dysfunction that may impair an elderly patient's ability to recover from surgery. The heart team cohort had more chronic obstructive pulmonary disease but less pneumonia and prolonged ventilation than the group not evaluated by a heart team in which almost a quarter of the in-hospital deaths were related to respiratory failure. The authors also suggest that hear team evaluation helped avoid concomitant procedures that added to the operative risk without helping the outcomes.

We congratulate the authors on approaching the question of heart team value in the treatment of aortic stenosis. Capturing the value of the heart team approach is no simple task. The presented data were accrued before low-risk TAVR and even any significant intermediate-risk TAVR was being done. Age, life expectancy, anatomic suitability for transfemoral TAVR, other relevant cardiac pathology, and patient wishes in consideration of the risks and benefits involved now should frame the decision process. Weighing all the aspects and uncertainties involved can be complex, even for experts. For patients, this requires long and through discussions, revisiting the issues from different angles, to make an informed treatment decision. This is where a functional heart team provides a platform to not find right in isolation, but better more often in a collaborative effort.

Finally, the current guidelines suggest TAVR as the best therapy for any patient older than age 80 years who is anatomically suitable for TAVR. But not all octogenarians with symptomatic severe aortic stenosis will be appropriate candidates for TAVR. The authors have also shown that with careful selection, appropriate patients older than age 80 years may be referred for SAVR with excellent outcomes. The move to younger, lower-risk patients with longer expected life only increases the importance of choosing wisely and helping our patients make informed decisions.

\section{References}

1. Serruys PW, Morice MC, Kappetein AP, Colombo A, Holmes DR, Mack MJ, et al Percutaneous coronary intervention versus coronary-artery bypass grafting for severe coronary artery disease. $N$ Engl J Med. 2009;360:961-72.

2. Mack MJ, Leon MB, Thourani VH, Makkar R, Kodali SK, Russo M, et al. Transcatheter aortic-valve replacement with a balloon-expandable valve in low-risk patients. N Engl J Med. 2019;380:1695-705.

3. Popma JJ, Deeb GM, Yakubov SJ, Mumtaz M, Gada H, O'Hair D, et al. Transcatheter aortic-valve replacement with a self-expanding valve in low-risk patients. N Engl J Med. 2019;380:1706-15.

4. Otto CM, Nishimura RA, Bonow RO, Carabello BA, Erwin JP III, Gentile F, et al 2020 ACC/AHA guideline for the management of patients with valvular heart disease: a report of the American College of Cardiology/American Heart Association joint committee on clinical practice guidelines. Circulation. 2021;143:e72-227.

5. Falk V, Baumgartner H, Bax JJ, De Bonis M, Hamm C, Holm PJ, et al. 2017 ESC/ EACTS guidelines for the management of valvular heart disease. Eur J Cardiothorac Surg. 2017;52:616-64.

6. Porterie J, Dumont E, Paradis J-M, De Larochellière R, Mohammadi S. Clinical impact of the heart team on the outcomes of surgical aortic valve replacement among octogenarians. J Thorac Cardiovasc Surg. 2023;165:1010-9.e5. 